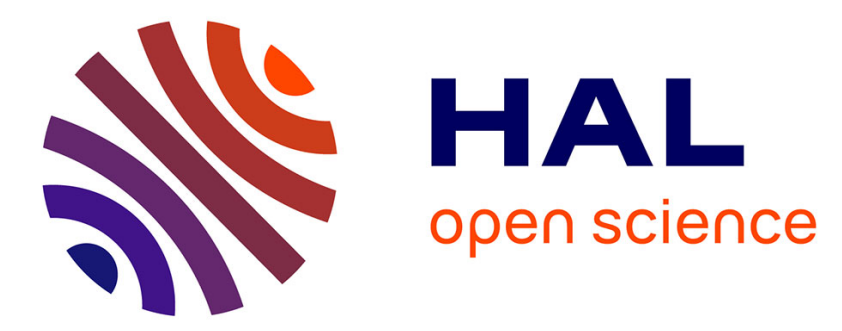

\title{
An Auger and XPS survey of cerium active corrosion protection for AA2024-T3 aluminum alloy
}

Arnaud Uhart, Jean-Bernard Ledeuil, Danielle Gonbeau, Jean-Charles Dupin, Jean-Pierre Bonino, Florence Ansart, Julien Esteban

\section{To cite this version:}

Arnaud Uhart, Jean-Bernard Ledeuil, Danielle Gonbeau, Jean-Charles Dupin, Jean-Pierre Bonino, et al. An Auger and XPS survey of cerium active corrosion protection for AA2024-T3 aluminum alloy. Applied Surface Science, 2016, 390, pp.751-759. 10.1016/j.apsusc.2016.08.170 . hal-01454825

\section{HAL Id: hal-01454825 \\ https://hal.science/hal-01454825}

Submitted on 8 Feb 2017

HAL is a multi-disciplinary open access archive for the deposit and dissemination of scientific research documents, whether they are published or not. The documents may come from teaching and research institutions in France or abroad, or from public or private research centers.
L'archive ouverte pluridisciplinaire HAL, est destinée au dépôt et à la diffusion de documents scientifiques de niveau recherche, publiés ou non, émanant des établissements d'enseignement et de recherche français ou étrangers, des laboratoires publics ou privés. 


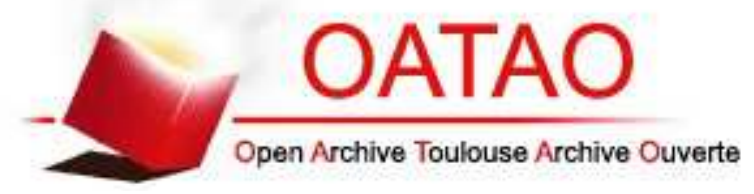

\section{Open Archive TOULOUSE Archive Ouverte (OATAO)}

OATAO is an open access repository that collects the work of Toulouse researchers and makes it freely available over the web where possible.

This is an author-deposited version published in : http://oatao.univ-toulouse.fr/ Eprints ID : 16639

To link to this article : DOI:10.1016/j.apsusc.2016.08.170

URL : http://dx.doi.org/10.1016/j.apsusc.2016.08.170

To cite this version : Uhart, Arnaud and Ledeuil, Jean Bernard and Gonbeau, Danielle and Dupin, Jean-Charles and Bonino, Jean-Pierre and Ansart, Florence and Esteban, Julien An Auger and XPS survey of cerium active corrosion protection for AA2024-T3 aluminum alloy. (2016) Applied Surface Science, vol. 390. pp. 751-759. ISSN 0169-4332

Any correspondence concerning this service should be sent to the repository administrator: staff-oatao@ listes-diff.inp-toulouse.fr 


\title{
An Auger and XPS survey of cerium active corrosion protection for AA2024-T3 aluminum alloy
}

\author{
A. Uhart ${ }^{\mathrm{a}}$, J.B. Ledeuil ${ }^{\mathrm{a}, \mathrm{b}}$, D. Gonbeau ${ }^{\mathrm{a}}$, J.C. Dupin ${ }^{\mathrm{a}, *}$, J.P. Bonino ${ }^{\mathrm{b}}$, F. Ansart $^{\mathrm{b}}$, J. Esteban ${ }^{\mathrm{c}}$ \\ a IPREM-ECP-UMR CNRS 5254, Université de Pau et des Pays de l'Adour, Technopole Hélioparc, 2 Avenue Président Pierre Angot, 64053 Pau Cedex 09, France \\ ${ }^{\mathrm{b}}$ Université de Toulouse, UPS-INP-CNRS, Institut Carnot CIRIMAT, 118 Route de Narbonne, 31062 Toulouse Cedex 09, France \\ ${ }^{\mathrm{c}}$ Messier-Bugatti-Dowty, Etablissement de Molsheim, 3, rue Antoine de St Exupéry, 67129 Molsheim, France
}

\author{
Keywords: \\ XPS \\ Auger \\ Cerium \\ Conversion coating \\ AA2024 alloy \\ Corrosion
}

\section{Introduction}

Aluminum and its alloys are widely used in aerospace industry because of their low density and mechanical properties. Despite the protective film ((hydro) oxide thin film) formed in moisture conditions, the high reactivity commonly observed drastically increases in contact with solutions containing complexing agents (e.g., halides) [1-4]. The corrosion process of aluminum involves the adsorption of aggressive ions on the (hydr)oxide aluminum surface (e.g., $\mathrm{Cl}^{-}$), the dissolution of this protective layer and the direct attack of the metal [5]. A solution to improve the corrosion resistance is to use protective coatings. Chromates $\left(\mathrm{Cr}^{\mathrm{VI}}\right)$ compounds are the most common substances used due to their efficiency in severe atmosphere and their low cost [6]. Chromates can be introduced by three main ways: direct incorporation into conversion coatings, only added in anodizing baths and as pigments in painting primers. However, the use of chromates in coatings involved serious environmental problems for the surface treatment industry, because hexavalent chromates are carcinogenic and highly toxic [5]. Since environmental regulations got stricter in the last few years, with the coming prohibition use of $\mathrm{Cr}^{\mathrm{VI}}$ compounds in corrosion protection

\footnotetext{
* Corresponding author.

E-mail address: dupin@univ-pau.fr (J.C. Dupin).
}

systems (REACH, 2017), different alternative substitution formulations have been extensively studied. One of the most promising systems is based on rare-earth (Ce, Nd, La, Y) impregnation solutions [7-9]. Moreover, Hinton et al. have revealed the high potential of cerium ions in the reduction of the corrosion rate [7]. Some new composite formulations (e.g., Ce-doped sol-gel network) offer both active (electrochemical) and passive (barrier) protection for the underlying alloys $[2,4,10,11]$. The idea of Ce conversion coatings as active protection films on aluminum alloys is still a key parameter in the general thought and recent works even recognized an enhanced activity with a prior acid surface pre-treatment [12]. All these preliminary studies inspired an increasing interest for researchers and especially aircraft manufacturers who want to progress in the knowledge of the active protection film formation process to optimize the life cycle of the coated devices. The Ceriumbased conversion process has already been undertaken with the different cerium salts [13] and, for each of them, with the addition (or not) of different sodium salts. Main observations were the nitrate ion proved to be a strong inhibitor and the sulphate ion had no marked effect (only very slight inhibition).

The purpose of this paper is to give complementary information in the topic about the role of cerium inhibitor via the study of the conversion coating (CC) composition by a dual X-Ray photoelectron (XPS)/Auger spectroscopies analysis. For a convenient protective process used in the industry, such a conversion coating 
is always pre-deposited onto the metal support before a primer (filler, UV absorber, ....) and topcoat (against mechanical abrasion and environmental erosion) [14]. Then, specific properties of the Cerium CC discussed here after have to be considered in a global framework. The corrosion protection of the some parts used in the aeronautics is then the good alchemy between the active (CC) and the passive (primer/paint) assemblies of the whole protective system. Our short study, only focused on the active protection deposit, presents an original survey, at the sub-micron scale, of the chemical evolution in the surrounding of the corroded zones (pits, crevices). With these adapted tools of surface characterization, migration of entities and changes into oxidation states are directly and simultaneously recorded. The real role of the active CC layers can be then well understood.

\section{Materials and methods}

\subsection{Material and treatments}

The material studied was $A A$ 2024-T3 aluminum alloy composed by (in wt\%) 3.8-5.0 Cu, 0.2-1.2 Mg, 0.4-1.0 Mn, 0.5-1.2 Si, <0.7 Fe, $<0.1 \mathrm{Cr}$. Each sample surface $(80 \mathrm{~mm} \times 42 \mathrm{~mm} \times 1 \mathrm{~mm}$ panel) was cleaned and prepared using several steps; after acetone degreasing, a chemical pretreatment was performed as it follows: a 20-min immersion in a $\mathrm{NaOH}$ solution $(\mathrm{pH}=9)$ maintained at $60^{\circ} \mathrm{C}$, followed by a rinsing with deionized water; and a 5 min neutralization in an aqueous solution of $\mathrm{NaNO}_{3}$ at $\mathrm{pH}=0.95$ at room temperature. The samples were finally washed in ethanol and dried in air.

Cerium based conversion coatings (Ce CC) were deposited at room temperature by immersion of the alloy panel in a water solution containing $\mathrm{Ce}\left(\mathrm{NO}_{3}\right)_{3}, 6 \mathrm{H}_{2} \mathrm{O}$ (Fluka, CAS: 10294-41-4) at a different cerium concentrations $(0.01 \mathrm{M}, 0.05 \mathrm{M}, 0.1 \mathrm{M}$ and $0.5 \mathrm{M})$. The $\mathrm{pH}$ of the immersion bath is maintained to 4 and no accelerating agent (e.g., $\mathrm{H}_{2} \mathrm{O}_{2}$ ) was used. Once immersed during $300 \mathrm{~s}$ (due time for a homogeneous/covering film and better electrochemical performance), samples were rinsed four times with deionized water and dried at room temperature in a desiccator. Ce CC were finally about $2.1 \pm 0.5 \mu \mathrm{m}$ thick (examined by SEM) with yellow/brown colorization, after a $300 \mathrm{~s}$ immersion in the conversion bath.

Aqueous corrosion solutions-Corrosion attack was conducted on the samples in a $3.5 \mathrm{wt} . \% \mathrm{NaCl}$ solution at $25^{\circ} \mathrm{C}$. Time of immersion was set to $1 \mathrm{~h}$ according to the appearance of first corrosion pits. A single and specific test of ionic cross section was achieved on the AA2024 substrate covered with Ce-based coating ([Ce] $=0.1 \mathrm{M}$ ) with a JEOL IB-0901 cross polisher. Analytical conditions are reported elsewhere in a recent work [15]. After $96 \mathrm{~h}$ under air exposure, samples surface and cross section were analyzed with XPS and Auger; this operation was a first try to investigate the corrosion propagation and the effect of the inhibitor deep in the material.

The electrochemical behavior of the systems was evaluated by electrochemical impedance spectroscopy (EIS) in a $0.05 \mathrm{M} \mathrm{NaCl}$ static solution $(\mathrm{pH}=6.0)$ for the different panels originaly got from several immersion times (1s, 60 s and 300s) in the conversion bath. For the electrochemical measurements, a three-electrode electrochemical cell was used, consisting of a platinum counter electrode, a saturated calomel reference electrode and the sample was used as a working electrode, with an exposed area equal to $15 \mathrm{~cm}^{2}$. The experimental apparatus used for the electrochemical investigation was a potentiostat (AUTOLAB PGSTAT 30) and a frequency response analyzer (FRA). EIS measurements were performed in potentiostatic mode at the OCP, obtained after a $1 \mathrm{~h}$ stabilization of the potential in the electrolyte. The amplitude of the EIS perturbation signal was $10 \mathrm{mV}$, and the frequency studied ranged from $100 \mathrm{kHz}$ to $10 \mathrm{mHz}$. Only values of the charges transfer resistance (R) are reported elsewhere in the text for any concentrations of cerium tested in the conversion bath.

\subsection{Surface analysis}

\subsubsection{Morphology of materials with scanning electron microscopy (SEM)}

The morphology and the microstructure of the coatings, before and after the immersion tests in corrosion solutions, were observed by Scanning Electron Microscopy (SEM). High resolution highenergy images were obtained with a JEOL JAMP-9500F Auger spectrometer (JEOL Ltd, Tokyo, Japan) working under precise conditions $\left(30 \mathrm{keV}, 2 \mathrm{nA}\right.$, working distance $=23 \mathrm{~mm}$, pressure $<2.10^{-7} \mathrm{~Pa}$ ) fitted with a Schottky field emission electron gun using a conventional secondary electron detector (SED) in the analysis chamber. The present analysis mode permits a high depth field for nanoparticles visualization.

\subsubsection{Surface chemical analysis with $X$-ray photoelectron spectroscopy (XPS)}

In the aim to characterize the Ce CC composition, X-Ray Photoelectron Spectrometry (XPS) measurements were performed on a Thermo K-alpha spectrometer with a hemispherical analyzer and a microfocussed (analysis area was c.a. $400 \mu \mathrm{m}^{2}$ ) monochromatized radiation ( $\mathrm{AlK} \alpha, 1486.6 \mathrm{eV}$ ) operating at $72 \mathrm{~W}$ under a residual pressure of $1 \times 10^{-9} \mathrm{mbar}$. The pass energy was set to $20 \mathrm{eV}$. Charge effects were compensated by the use of a charge neutralisation system (low energy electrons) which had the unique ability to provide consistent charge compensation. All the neutraliser parameters remained constant during analysis and allow ones to find a $285.0 \mathrm{eV} \mathrm{C1} \mathrm{s}$ binding energy for adventitious carbon. Spectra were mathematically fitted with Casa XPS software using a least squares algorithm and a non-linear baseline. The fitting peaks of the experimental curves were defined by a combination of Gaussian (70\%) and Lorentzian (30\%) distributions. Only core levels spectra for the elements with highest photoionization cross section were recorded in order to extract more reliable information.

\subsubsection{Surface chemical analysis with auger spectroscopy (XPS) \\ and chemical mapping with scanning auger microscopy (SAM)}

The Auger analyses were carried out with the previous JEOL JAMP 9500F Auger spectrometer working under UHV conditions (pressure $<2.10^{-7} \mathrm{~Pa}$ ). The UHV equipment was a Schottky field emission Auger electron spectrometer (FE-AES) dedicated to very high spatial resolution analysis and high brightness. The hemispherical electron analyzer coupled with a multichannel detector (7 channeltrons) offered ideal settings for energy resolved Auger analysis.

\section{Results and discussion}

\subsection{AA2024-T3 surface preparation}

The AA2024-T3 alloy surface was initially cleaned before Ce CC as reported in the Materials and treatment section. The chemical surface state is controlled with the XPS and results show a high initial content of hydrocarbon entities at the AAl2024-T3 surface (Fig. 1A).

The surface is full contaminated as no alloy elements are visible. Once chemically treated with acid and alkaline baths (Fig. 1B), the near alloy surface exhibits a clear decrease of the carbon component (Table 1) and an aluminum signal with two distinct components: - at $71.8 \mathrm{eV}$ associated with the metallic $\mathrm{Al}^{\circ}$ oxidation state, - and at $74.6 \mathrm{eV}$ corresponding to $\mathrm{Al}-\mathrm{O}(\mathrm{H})$ environment; the thin native (hydro)oxide overlayer is a potential anchorage area for the future conversion coating. Copper $\mathrm{Cu} 2 \mathrm{p}$ signal attests of the bare metal 


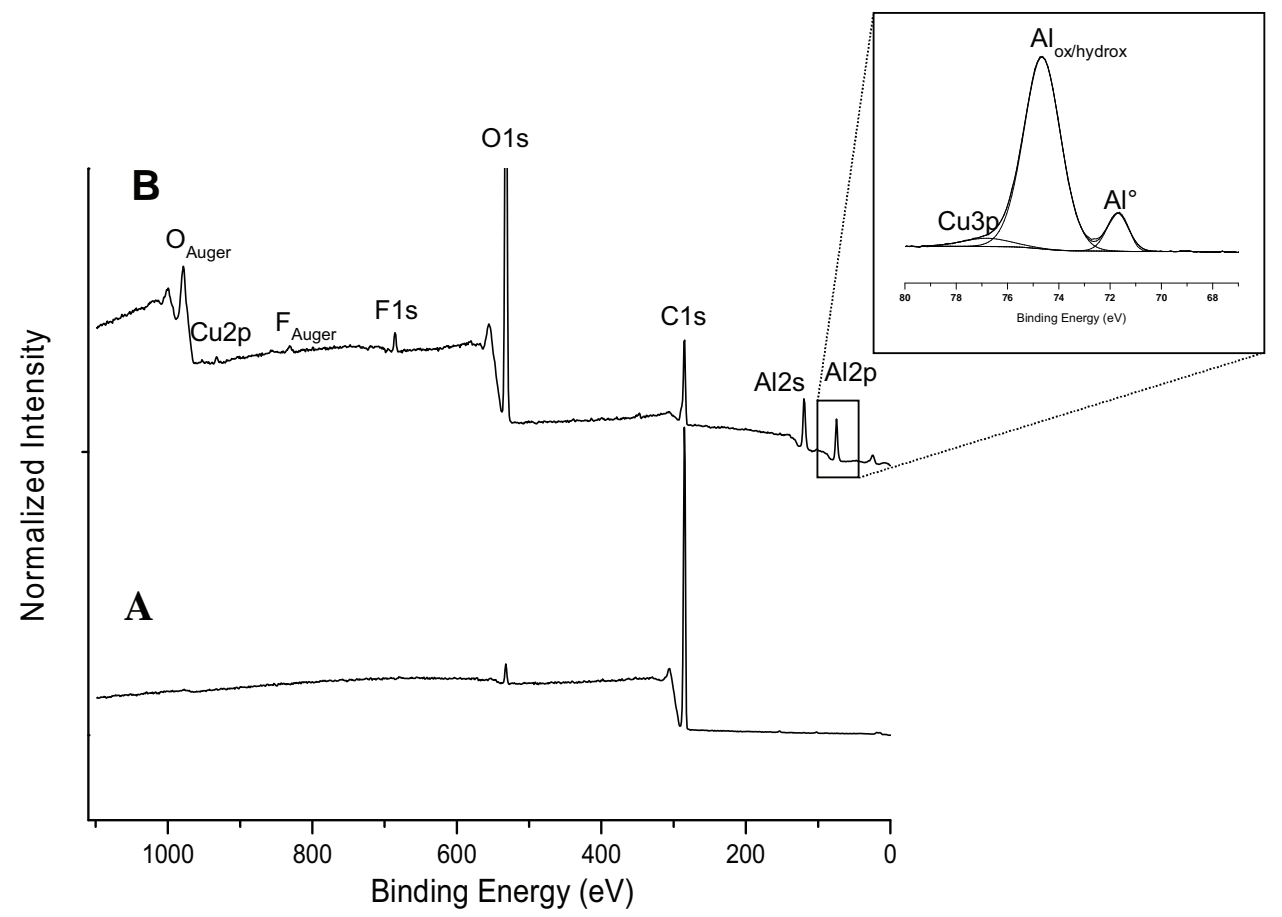

Fig. 1. Large scale XPS spectrum of AA 2024-T3 alloy: (A) before and (B) after surface preparation (degreasing/acid cleaning).

Table 1

Surface composition of the AA2024-T3 substrate: before and after degreasing/acid treatment and covered with $\mathrm{Ce} C \mathrm{C}([\mathrm{Ce}]=0.1 \mathrm{M})$ after $300 \mathrm{~s}$ of immersion in the conversion bath.

\begin{tabular}{llllllll}
\hline Element (at.\%) & $\mathrm{C}$ & $\mathrm{O}$ & $\mathrm{Al}$ & $\mathrm{Ce}$ & $\mathrm{N}$ & $\mathrm{Cu}$ & $\mathrm{F}$ \\
\hline Before surface preparation & 96.5 & 3.5 & - & - & & - & - \\
After surface preparation & 27.1 & 46.3 & 25.5 & - & & 0.2 & 0.9 \\
AA 2024-T3/CeCC $([\mathrm{Ce}]=0.1 \mathrm{M})$ & 31.0 & 46.8 & 3.8 & 12.2 & 6.2 & - & - \\
\hline
\end{tabular}

detection and the efficiency of the cleaning treatment. Effective cleaning pre-treatments are often demonstrated to be associated with the generation of surface defaults, grained topology favoring redox reactions necessary to the Ce CC formation [16].

Fluorine components of low intensity observed in the clean sample spectrum come from a residual pollution in the analysis chamber in the period of the experiment. It does not have any effect onto the surface chemistry as it has been mainly found, in very low concentration (around 0.9 at.\%), bonded to residual hydrocarbon entities.

\subsection{Ce-based conversion coating (Ce CC) over AA 2024-T3 before corrosion}

The Ce CC covering is expected to be quite homogeneous which is fundamental for the future industrial applications. SEM images of the Ce CC panels surface were systematically recorded in the different immersion conditions ([Ce], immersion time). Before corrosion, the appearance of the surface coating is quite homogeneous for cerium concentrations ranging from $0.01 \mathrm{M}$ to $0.1 \mathrm{M}$ whatever the immersion time. On figure ESI1, one can observe in the case of the $\mathrm{Ce}(0.1 \mathrm{M}) \mathrm{CC}$ coating ( $300 \mathrm{~s}$ of immersion) a surface rarely affected by topography defects (holes, excrescences, ...). When increasing the cerium concentration (e.g., $[\mathrm{Ce}]=0.5 \mathrm{M}$ ), right from the first seconds of immersion, the coating is cracked and can peel off for longer stay in the conversion bath. Then the higher the cerium concentration is, the more defective the coating surface becomes.
XPS analysis for the coated panels has shown well-identified chemical entities from the coating but also from the AA2024 substrate. For instance, after $300 \mathrm{~s}$ of immersion in the conversion bath, the large scale survey (Fig. 2A) of AA 2024-T3/Ce CC (e.g., $[\mathrm{Ce}]=0.1 \mathrm{M}$ ) system displays emergence of the main different orbitals ( $\mathrm{Al} 2 \mathrm{p}, \mathrm{Al} 2 \mathrm{~s}, \mathrm{C} 1 \mathrm{~s}, \mathrm{O} 1 \mathrm{~s}$ and $\mathrm{Ce} 3 \mathrm{~d}$ ) with intense signals (Table 1 ). The coating, very few microns thick, appears to be quite homogeneous and leveling (Fig. 2B) but the observation of some substrate elements with the XPS technique would attest of a certain porosity of the deposit. After $1 \mathrm{~s}$ of immersion, The XPS data give, at the substrate surface, a Ce/Al ratio between 0.4 and 0.5 for $[\mathrm{Ce}]=0.1 \mathrm{M}$ when it is 6 times higher for the $[\mathrm{Ce}]=0.5 \mathrm{M}$ in relation with a real difference of deposit thickness. For longer times of immersion (e.g. 300s), the $\mathrm{Ce} / \mathrm{Al}$ ratio is quite stable for $0.1 \mathrm{M}$ whereas it drastically drops for $0.5 \mathrm{M}$. This could confirm the damaging increase of the coating at high cerium concentration with the immersion time.

Different areas of analysis were pointed out and no difference was found for the chemical composition of the Ce CC coating traducing a good homogeneity. The cerium corrosion inhibitor has been recorded in quite important at\% between $2.6 \%$ (for $[\mathrm{Ce}]=0.01 \mathrm{M}$ ) to $13.7 \%$ for $[\mathrm{Ce}]=0.5 \mathrm{M}$ ). For all the coatings, the chemical survey attests of a mixture of cerium species ( $\mathrm{Ce}+\mathrm{III}$ and $\mathrm{Ce}+\mathrm{IV}$, see figure ESI2) as reported elsewhere [17]. Histograms show a main proportion of $\mathrm{Ce}+\mathrm{IV}$ for panels covered up at low cerium concentration when $\mathrm{Ce}+\mathrm{III}$ is in the majority for higher cerium concentration.

In the high resolution Ce3d spectrum, a same structured experimental profile is recoreded whatever the different cerium concentration of the $\mathrm{CC}$ bath and immersion times. Only intensities vary according to the content of $\mathrm{Ce}+\mathrm{III}$ and $\mathrm{Ce}+\mathrm{IV}$ species. In Fig. $3 \mathrm{~A}$ and the Table 2 (e.g., $\mathrm{Ce}(0.1 \mathrm{M}) \mathrm{CC}$ immersed 300 s), four main peaks corresponding to the pairs of spin-orbit doublets can be identified, in good agreement with other authors $[20,21]$ and the presence of a +III oxidation state. The highest binding energy peaks, $\mathrm{u}_{1}$ and $\mathrm{u}_{1}{ }_{1}$ respectively located at about $885.8 \pm 0.2 \mathrm{eV}$ and $904.3 \pm 0.2 \mathrm{eV}$ are the result of a Ce $3 \mathrm{~d}^{9} 4 \mathrm{f}^{1} \mathrm{O} 2 \mathrm{p}^{6}$ final state. The lowest binding energy states $\mathrm{u}_{0}$ and $\mathrm{u}_{0}$ respectively located at $881.8 \pm 0.2 \mathrm{eV}$ and $900.1 \pm 0.2 \mathrm{eV}$ are the result of Ce $3 \mathrm{~d}^{9} 4 \mathrm{f}^{2} \mathrm{O} 2 \mathrm{p}^{5}$. 


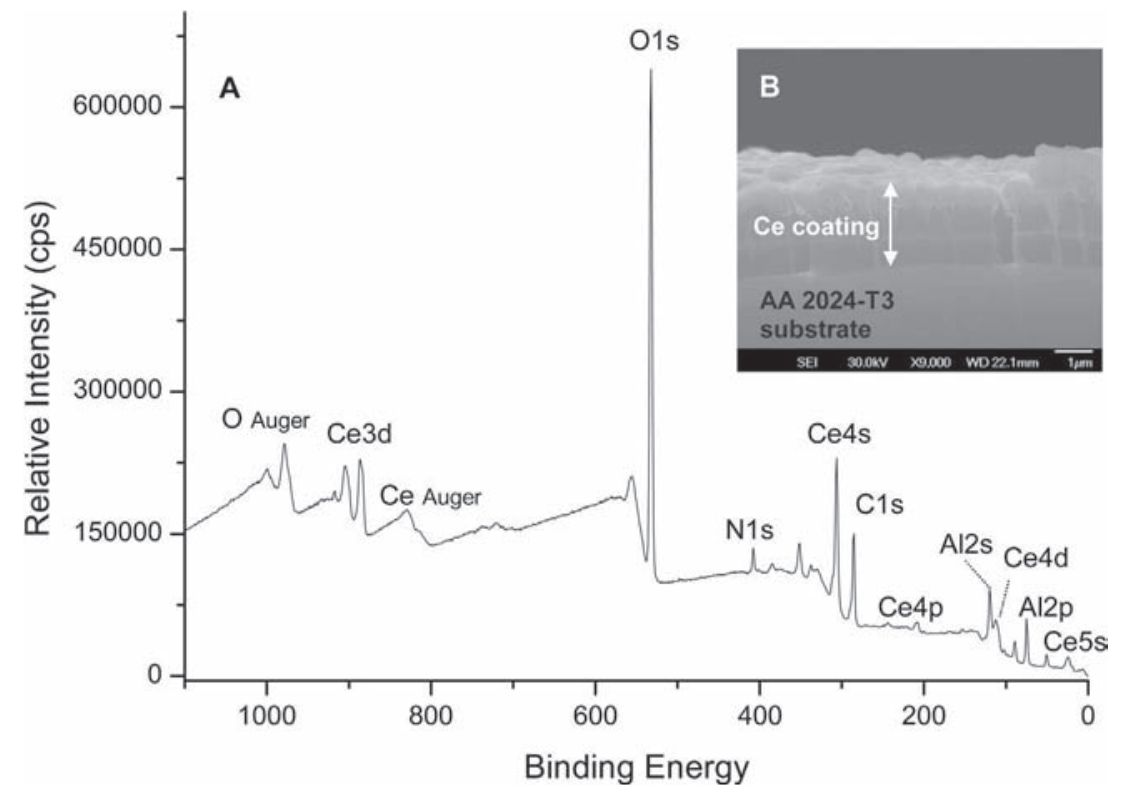

Fig. 2. Cerium-based conversion coating (with $[\mathrm{Ce}]=0.1 \mathrm{M}$; $300 \mathrm{~s}$ of immersion in the conversion bath) over AA2024-T3 alloy: (A) large scale XPS spectrum and (B) SEM micrograph of the cross section.

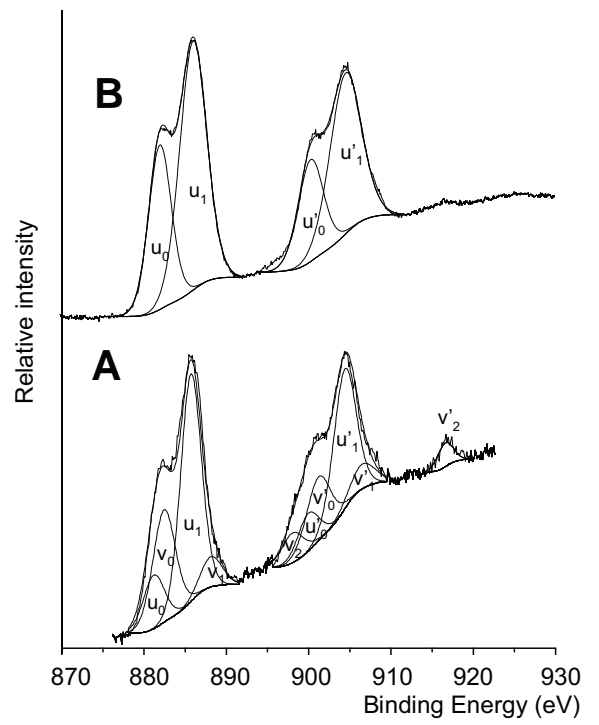

Fig. 3. XPS Ce3d spectrum of the Ce $(0.1 \mathrm{M}) \mathrm{CC}(300 \mathrm{~s}$ immersion time in the conversion bath)/AA2024-T3: (A) as-prepared and (B) after $180 \mathrm{~s}$ of compucentric $\mathrm{Ar}^{+}$ erosion (raster size: $0.8 \mathrm{~mm}$, IE: $3000 \mathrm{eV}$ ).

Table 2

Labeling, mean position of the 10 components of a mixed $\mathrm{Ce}(\mathrm{III}) / \mathrm{Ce}(\mathrm{IV})$ sample according to $\left({ }^{*}\right)$ mean position of peaks for the different $\mathrm{Ce}(0.1 \mathrm{M}) \mathrm{CC}(300 \mathrm{~s}$ immersion time) onto AA2024-T3 substrate.

\begin{tabular}{lllll}
\hline & & $\begin{array}{l}\text { Spin-orbit } \\
\text { component }\end{array}$ & $\begin{array}{l}\text { electronic state } \\
\text { attribution }\end{array}$ & $\begin{array}{l}\left({ }^{*}\right) \text { peak position } \\
(\mathrm{eV}) \pm 0.5 \mathrm{eV}\end{array}$ \\
\hline $\mathrm{Ce}(\mathrm{III})$ & $\mathrm{u}_{0}$ & $3 \mathrm{~d}_{5 / 2}$ & $\mathrm{Ce}(\mathrm{III}) 3 \mathrm{~d}^{9} 4 \mathrm{f}^{1}$ & 880.7 \\
& $\mathrm{u}_{0}{ }^{\prime}$ & $3 \mathrm{~d}_{3 / 2}$ & $\mathrm{O} 2 \mathrm{p}^{6}$ & 901.1 \\
& $\mathrm{u}_{1}{ }^{\prime}$ & $3 \mathrm{~d}_{5 / 2}$ & $\mathrm{Ce}(\mathrm{III}) 3 \mathrm{~d}^{9} 4 \mathrm{f}^{2}$ & 885.6 \\
& $\mathrm{u}_{1}{ }^{\prime}$ & $3 \mathrm{~d}_{3 / 2}$ & $\mathrm{O} 2 \mathrm{p}^{5}$ & 904.6 \\
$\mathrm{Ce}(\mathrm{IV})$ & $\mathrm{v}_{0}$ & $3 \mathrm{~d}_{5 / 2}$ & $\mathrm{Ce}(\mathrm{IV}) 3 \mathrm{~d}^{9} 4 \mathrm{f}^{2}$ & 882.5 \\
& $\mathrm{v}_{0}{ }^{\prime}$ & $3 \mathrm{~d}_{3 / 2}$ & $\mathrm{O} 2 \mathrm{p}^{4}$ & 903.4 \\
& $\mathrm{v}_{1}$ & $3 \mathrm{~d}_{5 / 2}$ & $\mathrm{Ce}(\mathrm{IV}) 3 \mathrm{~d}^{9} 4 \mathrm{f}^{1}$ & 886.8 \\
& $\mathrm{v}_{1}{ }^{\prime}$ & $3 \mathrm{~d}_{3 / 2}$ & $\mathrm{O} 2 \mathrm{p}^{5}$ & 907.5 \\
& $\mathrm{v}_{2}$ & satellite & $\mathrm{Ce}(\mathrm{IV}) 3 \mathrm{~d}^{9} 4 \mathrm{f}^{0}$ & 898.8 \\
& $\mathrm{v}_{2}{ }^{\prime}$ & satellite & $\mathrm{O} 2 \mathrm{p}^{6}$ & 916.7 \\
\hline
\end{tabular}

Some minor components owing to hybridization with ligand orbitals and partial occupancy of the valence $4 \mathrm{f}$ orbital are also observed. Six new peaks labeled $\mathrm{v}_{0}, \mathrm{v}_{1}, \mathrm{v}_{2}\left(\right.$ for $3 \mathrm{~d}_{5 / 2}$ ) and $\mathrm{v}_{0}{ }^{\prime}, \mathrm{v}_{1}{ }^{\prime}$, $v_{2}{ }^{\prime}\left(\right.$ for $3 d_{3 / 2}$ ) referring to the three pairs of spin orbit doublets are characteristic of $\mathrm{Ce}^{4+} 3 \mathrm{~d}$ final states $[22,23]$. The lowest binding energy states $\mathrm{v}_{0}\left(\mathrm{v}_{0}{ }_{0}\right), \mathrm{v}_{1}$ (and $\mathrm{v}_{1}{ }_{1}$ ) respectively located at $882.5 \mathrm{eV}$ (903.4 eV), 886.8 (and 907.5) are the result of Ce $3 d^{9} 4 f^{2} \mathrm{O}^{2} \mathrm{p}^{4}$ and Ce $3 \mathrm{~d}^{9} 4 \mathrm{f}^{1} \mathrm{O} 2 \mathrm{p}^{5}$ final states. The highest binding energy peaks, v2 and v'2 respectively located at about 916.7 and $898.8 \pm 0.2 \mathrm{eV}$ are the result of a Ce $3 \mathrm{~d}^{9} 4 \mathrm{f}^{0} \mathrm{O} 2 \mathrm{p}^{6}$ final state. The satellite peak v2 associated to the $\mathrm{Ce} 3 \mathrm{~d}_{3 / 2}$ is characteristic of the presence of tetravalent $\mathrm{Ce}(+\mathrm{IV}$ oxidation state) due to a partial oxidation of cerium in the reference material. This fact is pretty interesting as this component is isolated from the others at approx. $916-917 \mathrm{eV}$, as a matter of fact, one can use this peak as a quantitative probe of the amount of $\mathrm{Ce}(\mathrm{IV})[18,24-26]$.

In such a coating the minor $\mathrm{Ce}+\mathrm{IV}$ species seem to be located in the top layer part as demonstrated by soft $\mathrm{Ar}^{+}$ion erosion which reveals only a $\mathrm{Ce}+$ III state after $180 \mathrm{~s}$ of surface erosion (Fig. 3B). Such observations were even reported in a furnished work of L.S. Kasten and coll. [18]. $\mathrm{Ce}+\mathrm{IV}$ (deposition of $\mathrm{CeO}_{2}-2 \mathrm{H}_{2} \mathrm{O}$ or $\mathrm{Ce}(\mathrm{OH})_{4}$ layer) is found to be predominant under different experimental conditions: when the cerium-based conversion coating is achieved using, for instance, chloride cerium salt based conversion bath in presence of hydrogen peroxide [19]. At low Ce concentration, the smaller thickness of the deposit involves the oxidation of most dispersed $\mathrm{Ce}+$ III species which is less evident for thicker coating (high Ce concentration) for which only top layers of $\mathrm{Ce}+\mathrm{III}$ are oxidized. The oxidation effect is more pronounced for $\mathrm{Ce}(0.1 \mathrm{M}) \mathrm{CC}$ compare to $\mathrm{Ce}(0.5 \mathrm{M}) \mathrm{CC}$ certainly due to a more important porosity for this last one.

Indeed, it has been demonstrated that the integral area of $\mathrm{v}_{2}{ }^{\prime}$ peak with respect to the total $\mathrm{Ce} 3 \mathrm{~d}$ area could be translates into percentage of $\mathrm{Ce}^{4+}[24,27]$. Shyu and coll. [28] have demonstrated that the integral area of the $\mathrm{v}_{2}{ }^{\prime}$ peak with respect to the total Ce3d area could be translated into percentage of $\mathrm{Ce}^{4+}$ with the relative error of being in the range of $10 \%$. In the case of pure $\mathrm{Ce}^{4+}$, the $\mathrm{V}_{2}{ }^{\prime}$ peak should constitute around $14 \%$ of total integral intensity. According to the linear dependence of percentage $\mathrm{v}_{2}$ ' on percentage 


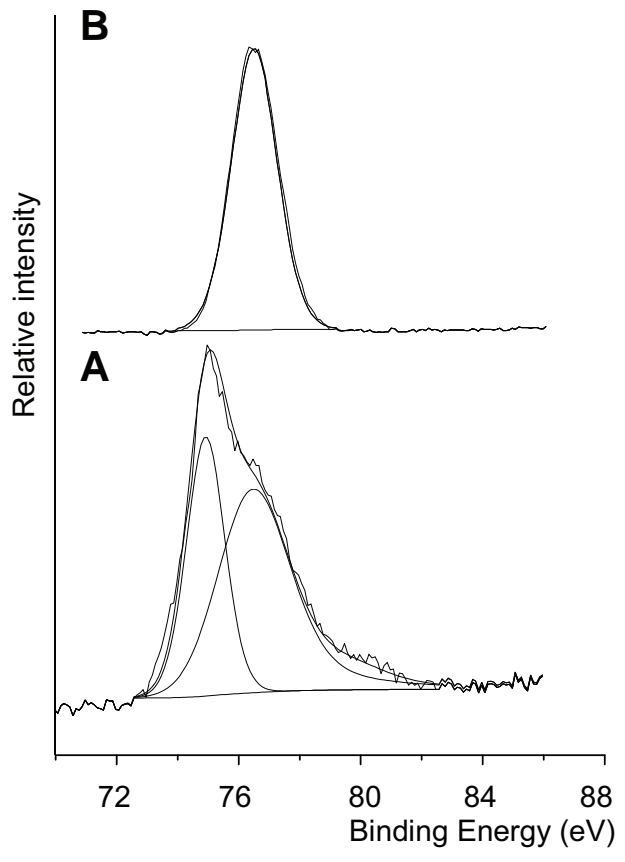

Fig. 4. XPS Al2p spectrum of: (A) Ce $(0.1 \mathrm{M}) \mathrm{CC}$ (300 s immersion time in the conversion bath)/AA2024-T3 and (B) $\mathrm{AlCeO}_{3}$ reference material.

$\mathrm{Ce}^{4+}$ reported in the literature, percentage of $\mathrm{Ce}^{4+}$ was calculated by:

$C e^{4+}=\frac{v_{2}^{\prime} \%}{14} \times 100$

where $\mathrm{v}_{2}{ }^{\prime} \%$ is the percentage of $\mathrm{v}_{2}{ }^{\prime}$ peak area with respect to the total Ce3d area.

For all the analyzed panels under different preparation conditions, the Al2p experimental is quite the same with a two components convolution. Fig. $4 \mathrm{~A}$ of $\mathrm{Ce}(0.1 \mathrm{M}) \mathrm{CC}$ immersed $300 \mathrm{~s}$ shows two chemical environments: the component at $74.8 \mathrm{eV}$ can be associated with the native oxide layer on top AA 2024-T3 substrate while the one on high energy side $(76.9 \mathrm{eV})$ is attributed to a $\mathrm{Al} / \mathrm{O} / \mathrm{Ce}$ mixed chemical environment as detected in a commercial stoichiometric $\mathrm{AlCeO}_{3}$ material (CAS 12014-44-7, Sigma-Aldrich) analyzed in same experimental conditions (Fig. 4B). Then part of the cerium entities seems to be located in the near surface of the alloy (near the $\mathrm{Al}$ oxide/hydroxide top layer) which could be a key point in the corrosion protection, in terms of proximity with the metal surface. The fact that one can observe the presence of aluminum, even if the coating is around $2.0 \mu \mathrm{m}$ thick, would also signify a certain porosity degree of the deposit.

Whatever the conditions of immersion time, a complementary survey of the surface sample was systematically done with an Auger mapping (SAM) analysis to control the spatial chemical homogeneity of chemical elements.

In Fig. 5, the case of the $\mathrm{Ce}(0.1 \mathrm{M}) \mathrm{CC}$ coating immersed $300 \mathrm{~s}$ in the conversion bath is presented and few surface defects (cracks, holes, ...) are noticed as discussed elsewhere, attesting of a good leveling deposit in the present conditions of deposit. The Auger mapping allows one to consider a good dispersal of cerium with the experimental deposit process used in this work. The observation of the aluminum and oxygen in quite good relative content confirms the native aluminum (hydro)oxide overlayer in the proximity of the cerium.

\subsection{Ce-based conversion coating (Ce CC) over AA 2024-T3 after corrosion}

\subsubsection{Corrosion resistance}

The electrochemical results (Fig. 6), indicate, after one second of immersion in a $0.05 \mathrm{M} \mathrm{NaCl}$ static solution $(\mathrm{pH}=6.0)$, that in controlled proportions, the addition of cerium in the conversion bath leads to the increase of the anti-corrosion properties. However, it seems there is a cerium concentration threshold $(0.1 \mathrm{M})$ over which the corrosion resistance fails. The coating doped with $0.5 \mathrm{M}$ $\mathrm{Ce}\left(\mathrm{NO}_{3}\right)_{3}$ shows the lowest resistance and the highest capacitances

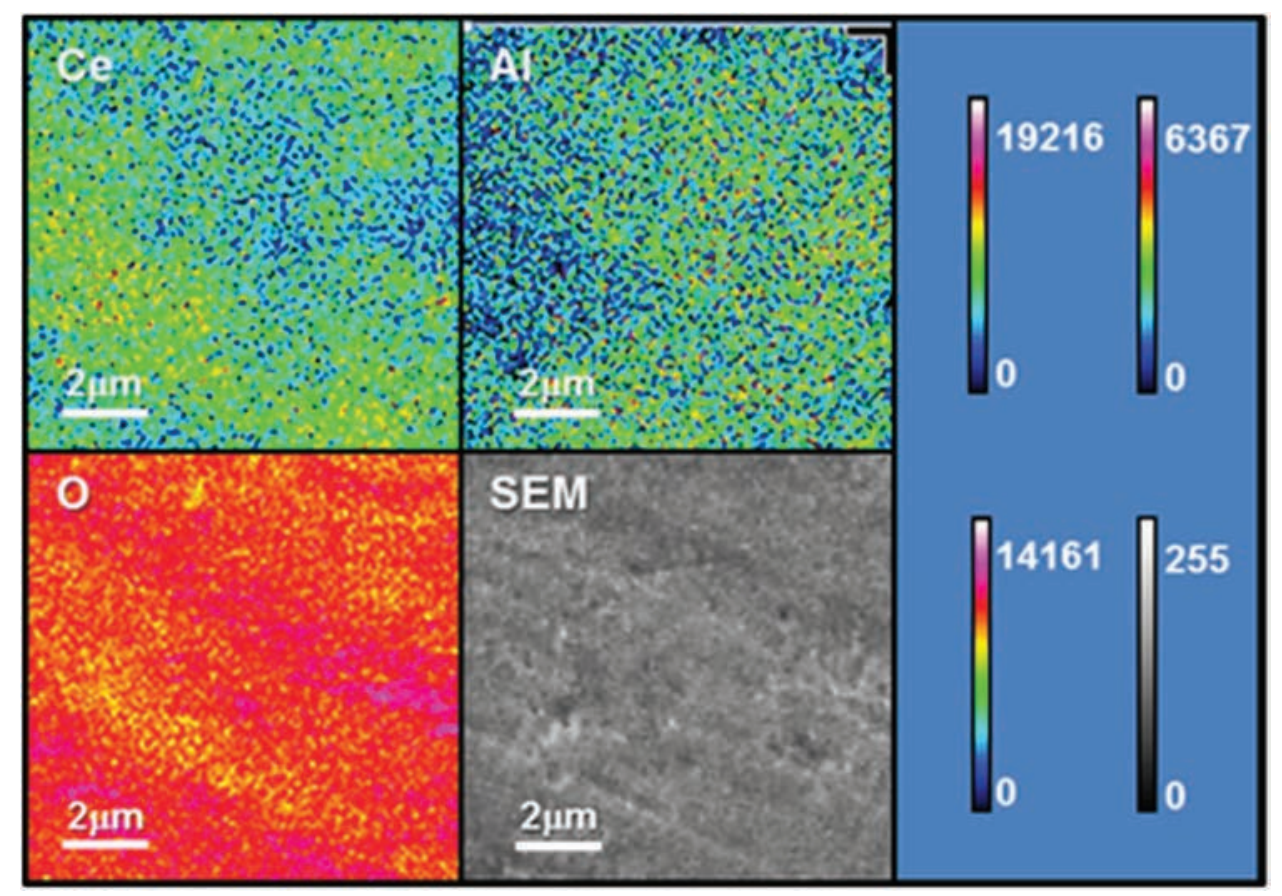

Fig. 5. $\mathrm{Ce}(0.1 \mathrm{M}) \mathrm{CC}$ coating (immersion time $=300 \mathrm{~s}$ in the conversion bath) as-prepared: SAM images for Ce, Al and O elements (RVB scale) and SEM micrograph of the same area (bottom right). 


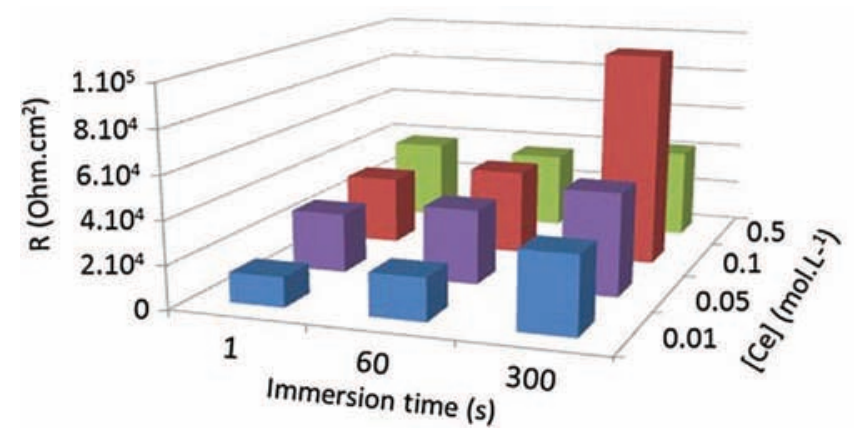

Fig. 6. Charges transfer resistance evolution of AA2024T3 panels immersed in some conversion baths of different cerium concentrations and for different times of immersion.

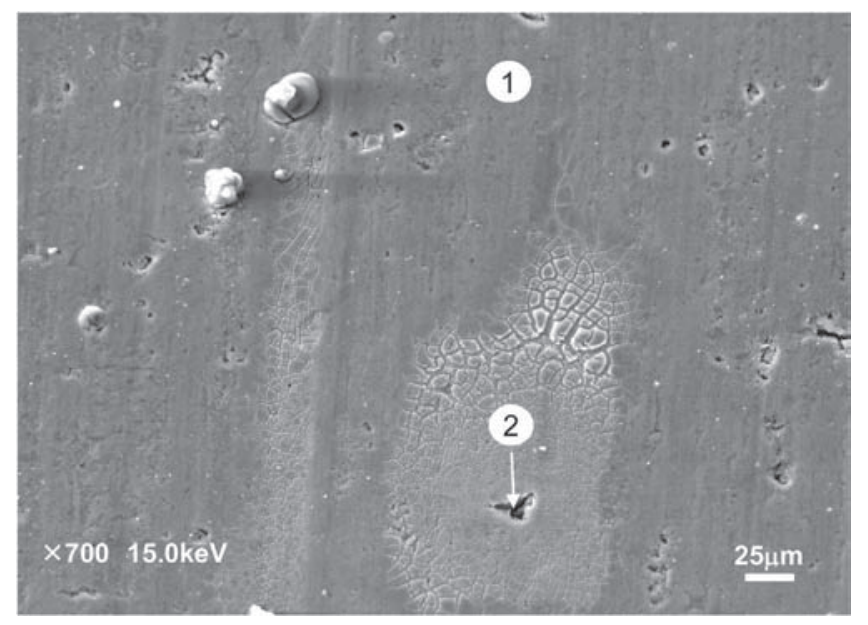

Fig. 7. (A) SEM micrograph of the corroded $\mathrm{Ce} C \mathrm{CC}(\mathrm{Ce}=0.1 \mathrm{M})$ applied onto AA 2024 T3 (300 s immersion time).

at the end of the test period, suggesting that the increase of the cerium concentration promotes the formation of more defective coatings. Moreover, the corrosion resistance is clearly enhanced after $300 \mathrm{~s}$ of immersion.

These events are probably due to the physico-chemical structuration of the Ce CC which could change with the cerium content (internal constraints). Actually, in relation with the effective role of $\mathrm{Ce}+\mathrm{III}$ ions extensively reported for the active protection of AA 2024-T3 alloy [6,29], the present study will only focus onto ceriumbased conversion coating (with $[\mathrm{Ce}]=0.1 \mathrm{M}$ ) for which the better corrosion resistance is reached after $300 \mathrm{~s}$ of substrate immersion in the conversion bath.

\subsubsection{Chemical analysis of the corrosion attack}

On the coated Ce CC panels, whatever their initial immersion time and Ce concentration proceeded in the conversion bath, first corrosion pits appeared before $1 \mathrm{~h}$ of immersion into the $3.5 \mathrm{wt} . \%$ $\mathrm{NaCl}$ solution. After $96 \mathrm{~h}$ under air exposure drying, panels were then analyzed with XPS, SEM and SAM. A global SEM micrograph for the treated substrate in the $3.5 \mathrm{wt} . \% \mathrm{NaCl}$ solution is presented in Fig. 7. It displays the presence of holes randomly dispersed at the surface and some zones highly damaged with a localized peel off phenomenon. The white nodules are well-known Cu-rich deposited particles (e.g., $\mathrm{Al}_{2} \mathrm{CuMg}$ metallic agglomerates ...) as detected with Auger spectroscopy and reported elsewhere [30-32]. The close-up SEM micrograph of a "zoom in" corrosion pit (Fig. 8) allows one to better appreciate details of the coating peel off state and a real change of color nuance in the damaged area suggesting a change in the chemical composition (different secondary electrons emission recorded).

The Auger chemical mapping achieved on the coating surface shows clear differences in the spatial distribution of cerium before (fig. 5) and after (fig. 8) the corrosion attacks of the coated panel. As the cerium is primarily well overlaid onto the substrate after the Ce CC immersion, it seems to move to the pits areas during the corrosion event. Actually a relative high content is observed in the hollow ring of the corrosion pit and in its center part. Color intensity gradient (in agreement with the relative concentration of the element) attests of a migration of cerium from surrounded zones to the corrosion pit. In the damaged zone, the relative concentration of cerium increases relate to the surrounding zones. This influx is certainly explained from the migration of cerium which ensures the active substrate protection against corrosion. In the attacked halo of the coating, cerium becomes more concentrated when relative aluminum and oxygen amounts fall down. This result is original and significant for the direct visualization of the corrosion inhibitor behavior and the protective action of Ce CC.

The chemical mapping of oxygen relative content shows less drastic change from the undamaged coating to the corrosion pit. This could correspond to the existence of cerium oxide/hydroxide in both areas with slightly stoichiometry differences. In another hand, aluminum is clearly withdrawn from the attacked zone. Some additional measurements were achieved with Auger spectroscopy in different points at the panel surface (figure ESI.3) before and after $1 \mathrm{~h}$ and $5 \mathrm{~h}$ of immersion in the corrosive $\mathrm{NaCl}$ bath. Quantification data, extracted from the convolution of Auger lines O KLL (510.0 eV), Al KLL (1387.0 eV) and Ce MNN (625.0 eV), clearly confirm the displacement of cerium in the corroded parts of the panel with an enhancement of its relative content during the corrosion process: 18.6 at.\% in the as prepared coating and up to 27.3 at.\% ( $1 \mathrm{~h}$ of immersion) and 39.4 at.\% ( $5 \mathrm{~h}$ of immersion) in the center damaged zone. The Auger spectroscopy and mapping is great complement to SEM surveys as the sole SEM images interpretation cannot explain the whole reality of the coating surface evolution. For instance in the case of the panel immersed during $1 \mathrm{~h}$ in the corrosive bath, it is easy to monitor the Ce migration with the Ce content from point 1 towards points 2 and 3 . This observation gives a real sense to the "active" protection of the inhibitor.

To go further in the understanding of chemical events during the corrosion process, a XPS survey has been run in two specific points of the corroded panel displayed in Fig. 7 (labelled 1 and 2). This specific zone was chosen because of the important size of the observed pit (around $60 \mu \mathrm{m} \times 130 \mu \mathrm{m}$ ) which fits with the used of the focused X-ray beam ( $30 \mu \mathrm{m}$ diameter). The aim of the XPS analysis was to precise the possible chemical changes during the cerium migration. For zone 1, the Ce3d spectrum (Fig. 9A) fits into two doublets assigned to a $\mathrm{Ce}+\mathrm{III}$ (hydro)oxidized environment with previously reported binding energies (U: $880.8 \mathrm{eV}-901.3 \mathrm{eV}$ ) and $(\mathrm{V}: 885.9 \mathrm{eV}-904.8 \mathrm{eV}$ ) for such oxidation state of cerium. As the surface has been exposed to the treatment solution, the near surface morphology has necessary changed to more roughness and the dissolution of the thin Ce+IV layer. The physical and chemical perturbation of the surface also influenced the Ce3d electron emission which displays a noisy signal. Loss of carbon atomic percentage combined with the enhancement of copper and aluminum elements signals of the substrate puts into evidence the $\mathrm{NaCl}$ attack on the coating. This phenomenon is more pronounced in the visible corrosion crack (zone 2 ) for which the Ce content strongly increased (Ce at.\% 2 times more important than in zone 1, see Table 3 ) and substrate is more visible as the coating peeled off in this zone. In the corrosion pit zone (2), a significant evolution of the Ce3d spectrum is noticed with the appearance $\mathrm{Ce}+\mathrm{IV}$ features and the specific satellite peak around $917 \mathrm{eV}$ (Fig. 9B). 


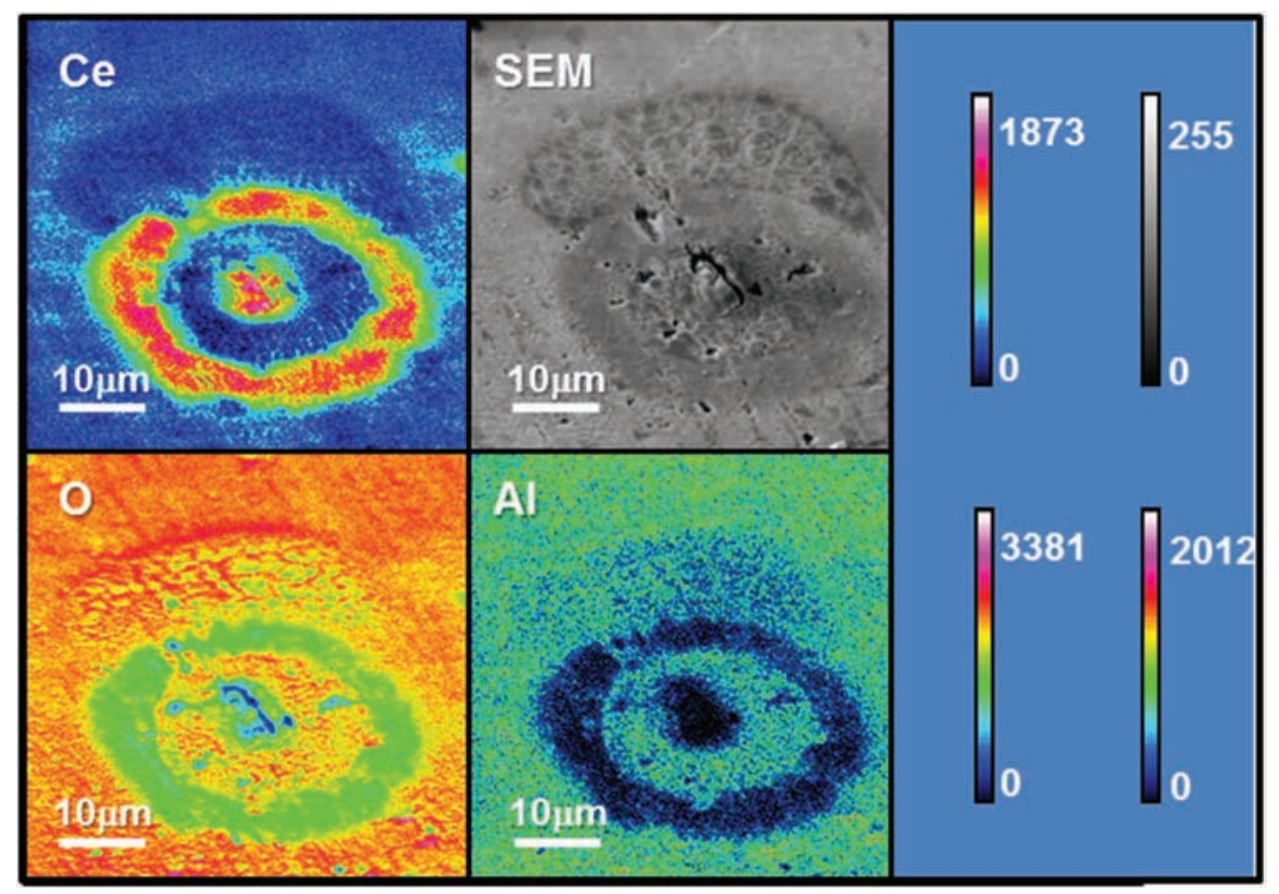

Fig. 8. $\mathrm{Ce}(0.1 \mathrm{M}) \mathrm{CC}$ coating (immersion time $=300 \mathrm{~s}$ in the conversion bath) after corrosion attack: SAM images for Ce, Al and O elements (RVB scale) and SEM image of the same area (top right).

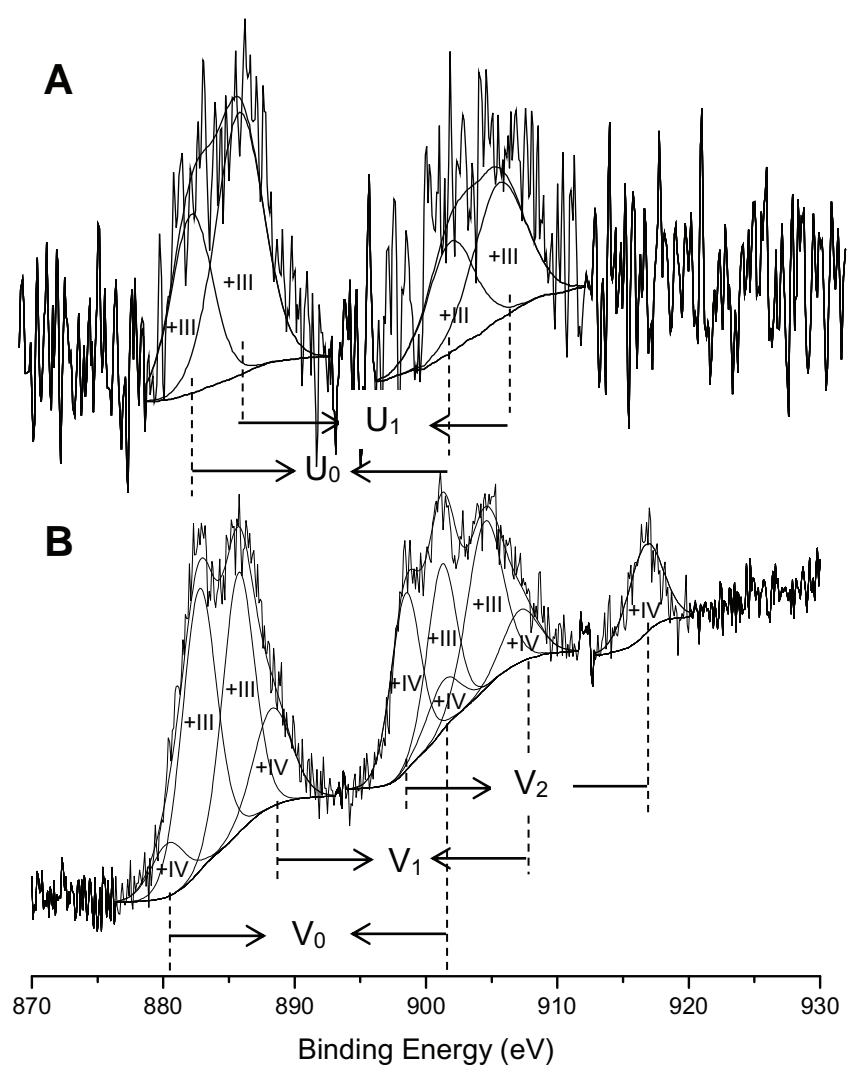

Fig. 9. XPS Ce3d peak of treated $\mathrm{Ce}=0.1 \mathrm{M}$ coating applied on AA 2024-T3: (A) zone 1 and (B) zone 2 of Fig. 7.

Then, it seems the cerium played its inhibitor role in the wounded zone with a great kinetic and its migration is accompanied with a chemical state transformation $(\mathrm{Ce}+\mathrm{III} \rightarrow \mathrm{Ce}+\mathrm{IV})$. The observation of the $01 \mathrm{~s}$ spectrum (Fig. 10) gives the same trend with the top heights of the experimental profile which shifted
Table 3

XPS Surface composition of zones 1 and 2 of the treated $\mathrm{Ce}=0.1 \mathrm{M}$ coating ( $300 \mathrm{~s}$ immersion time) applied onto AA 2024-T3.

\begin{tabular}{lllllllll}
\hline Element (at.\%) & $\mathrm{Cu}$ & $\mathrm{Ce}$ & $\mathrm{C}$ & $\mathrm{O}$ & $\mathrm{Al}$ & $\mathrm{N}$ & $\mathrm{Na}$ & $\mathrm{Cl}$ \\
\hline Zone 1 & 0.1 & 7.7 & 29.8 & 50.6 & 6.4 & 3.8 & 0.8 & 0.8 \\
Zone 2 & 0.4 & 15.0 & 25.3 & 43.1 & 14.5 & 1.2 & 0.3 & 0.2 \\
\hline
\end{tabular}

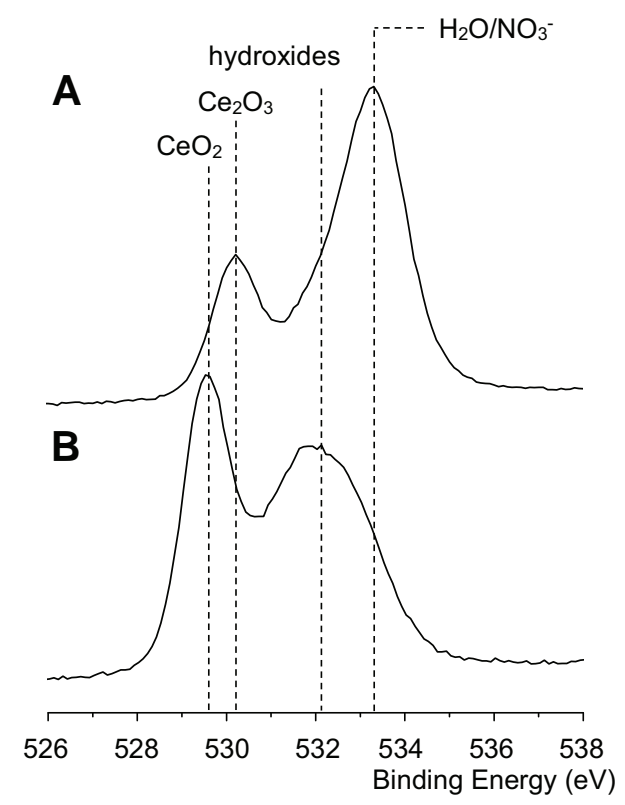

Fig. 10. XPS $01 \mathrm{~s}$ peak of treated $\mathrm{Ce}=0.1 \mathrm{M}$ coating applied on AA 2024-T3: $(\mathrm{A})$ zone 1 and (B) zone 2 of Fig. 7.

as the damage increase attesting of new electronic distribution around oxygen atoms. For zone 1 (fig. 10A), an intense component $(\mathrm{BE}=533.3 \mathrm{eV})$ associated with residual traces of nitrates from initial cerium salt and water from the treatment bath, is observed. 
A

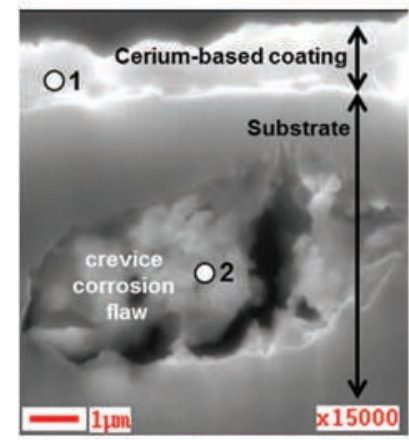

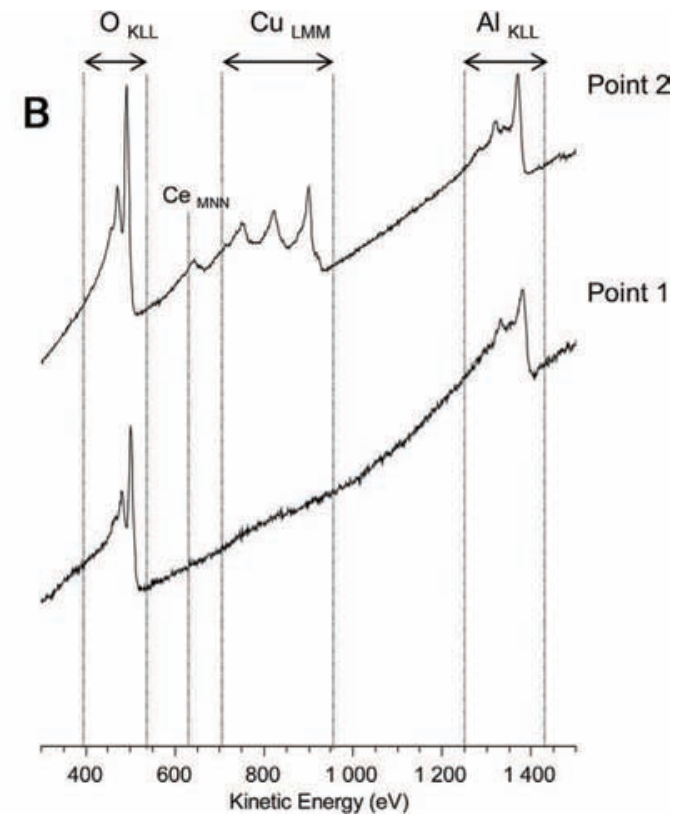

Fig. 11. Cross section of Cerium-based conversion coating (with $[\mathrm{Ce}]=0.1 \mathrm{M}$, immersion time: 300 s) over AA2024T3 alloy after $5 \mathrm{~h}$ corrosion into $3.5 \mathrm{wt}$.\% NaCl solution: (A) SEM view and (B) Auger spectroscopy analysis in the coating section (point 1) and within the crevice corrosion flaw (point 2).

The component at $532.1 \mathrm{eV}$ corresponds to the hydroxide species (hydroxilized carbon, $\mathrm{Al}(\mathrm{OH})_{3} \ldots$...) while the narrow component at $530.2 \mathrm{eV}$ can easily be associated to cerium sesquioxide [33]. In the area of the corrosion pit (zone2), the oxygen peak on low energy side (fig. 10B), shifts to $529.6 \mathrm{eV}$ which it is significant of a Ce + IV state as found in $\mathrm{CeO}_{2}$ [32]. A shoulder around $530.2 \mathrm{eV}$ is still visible as expected in the $\mathrm{Ce}+\mathrm{III} / \mathrm{Ce}+\mathrm{IV}$ mixture reported in the $\mathrm{Ce} 3 \mathrm{~d}$ spectrum (fig. 9B). In view of these results, a direct overview of the chemical changes occurring under the corrosive $\mathrm{NaCl}$ effect can be screened. Cerium acts as a self-healing agent in the Ce CC coating with appropriate migration to the bounded zones and the initiation of redox process to block the cathodic zones. Actually, the release of hydroxyls in the cathodic zones leads to the precipitation of cerium species mainly into intermediate hydroxides then into cerium dioxide.

In this respect, Aldykiewicz et al. [34] proposed that the cathodic deposition of $\mathrm{CeO}_{2}$ films was due to the oxidation in the solution of $\mathrm{Ce}^{3+}$ ions to tetravalent $\mathrm{Ce}(\mathrm{OH})_{2}{ }^{2+}$ ions in solution (which can diffuse reaching local defects) following the Pourbaix diagram [35]:

$4 \mathrm{Ce}^{3+}+6 \mathrm{H}_{2} \mathrm{O}+\mathrm{O}_{2} \rightarrow 4 \mathrm{Ce}(\mathrm{OH})_{2}{ }^{2+}+4 \mathrm{H}^{+}$

and precipitate according to the reaction:

$\mathrm{Ce}(\mathrm{OH})_{2}{ }^{2+} \rightarrow \mathrm{CeO}_{2}+2 \mathrm{H}^{+}$

To corroborate the migration of cerium species from the Cebased coating to the damaged zones of the AA2024 alloy, an original survey was focused deeper in the substrate after $5 \mathrm{~h}$ of corrosion attack (Fig. 11A). Substrate was cross-cut in the area of a well identified crevice corrosion flaw. The SEM micrograph reveals the inner morphology in the direction of the section, the unstructured Cebased coating over the substrate in accordance with the general degradation under corrosive conditions. In the center part of the micrograph, the substrate is consumed and a large crevice (undercut pit) extends over few microns. A local Auger chemical analysis in both zones (labeled 1 and 2 on Fig. 11A) was achieved to precise the chemical entities behavior during the corrosion mechanism. We focused the experiment on a $300 \mathrm{eV}-1500 \mathrm{eV}$ energy scale to get better resolution of the detected transitions. The Auger spectrum of the damaged Ce-based coating (Fig. 11B, point 1 ) mainly exhibits the Auger transitions of aluminum and oxygen. The absence of any cerium signal is significant of the complete dissolution of the Cebased layer or the migration of cerium entities deep in the material. The thickness of the observed top-layer over the AA2024-T3 substrate got thinner $(0.9 \mu \mathrm{m} \pm 0.2 \mu \mathrm{m})$ and would only be made of native aluminum (hydr)oxide phases and hydrocarbon (for carbon element, C KVV transition at $263 \mathrm{eV}$ can't be detected in the energy scale of the study). Within the crevice corrosion flaw, same analysis was run (Fig. 11B, point 2) and a new set of transitions is detected: Ce MNN (large component with top-height at $630 \mathrm{eV}$ ) and $\mathrm{Cu}$ LMM (series of transitions between $710 \mathrm{eV}$ and $902 \mathrm{eV}$ ). The co-presence of cerium, copper and aluminum was found in different other analyzed zones within the crevice. This main observation suggests the precise behavior of the corrosion inhibitor which would block the cathodic zones.

\section{Conclusion}

On the way of the knowledge and understanding of the corrosion protection of AA2024 alloy, the present paper gives a complementary view of the chemical evolutions at the surface of the substrate. Cerium conversion coating on prepared 2024 aluminum alloy consisted of Al oxide, and mainly of $\mathrm{Ce}+\mathrm{III}$ oxide and hydroxide. The $\mathrm{Ce}$ state exhibited a mixture of $\mathrm{Ce}+\mathrm{III}$ and $\mathrm{Ce}+\mathrm{IV}$ depending on the salt concentration in the conversion bath. The outer layer of the coating is $\mathrm{Ce}+\mathrm{IV}$ rich and it probably indicates the $\mathrm{Ce}+\mathrm{III}$ oxidized to $\mathrm{Ce}+\mathrm{IV}$ during coating formation in the initial solution. The comparison of Ce concentrations of the conversion has shown better charges transfer resistance (then better relative corrosion protection) for a panel immersed during $300 \mathrm{~s}$ in a $[\mathrm{Ce}]=0.1 \mathrm{M}$ bath. For higher Ce concentrations or immersion time, the deposit becomes more powdered and unsuitable to aircraft applications. The detailed XPS study has allowed one to consider a close-up interaction between cerium and the Al oxide layer on top alloy with the existence of $\mathrm{Al} / \mathrm{O} / \mathrm{Ce}$ mixed chemical environment. Microscopic and spectroscopic tools were even precious indicators to appreciate the cerium inhibitor behavior in term of displacement and chemical modification. The location of cerium has been monitored at any time with a precise SAM survey which is complex to set up but essential for an elemental screening within confined or very small zones of interest. Actually, under corrosive conditions, cerium tends to move, 
in a short time, towards wounded zones leaving the surrounding coating area almost free of inhibitor content. This direct action involves a chemical change with the formation of $\mathrm{Ce}+\mathrm{IV}$ oxide and hydroxide. Same observations were done at the substrate surface (corrosion pits) and sub-surface (crevices). The effectiveness of the Ce CC coating before the deposit of a primer and/or a final topcoat is determined by the synergy of many experimental parameters. Even if cerium alone cannot guarantee the whole protection of a metal panel against corrosion, it acts as a really active agent with a quick kinetic for healing wounded zones.

\section{Acknowledgments}

Thanks to the french aeronautics consortium (AESE pole SOLGREENC) and the DGA (Direction Générale de l'Armement) for their technical and financial support.

\section{Appendix A. Supplementary data}

Supplementary data associated with this article can be found, in the online version, at http://dx.doi.org/10.1016/j.apsusc.2016.08. 170.

\section{References}

[1] K.A. Yasakau, M.L. Zheludkevich, O.V. Karavai, M.G.S. Ferreir, Prog. Org. Coat. 63 (2007) 352-361.

[2] S.M. Tamborim, A.P.Z. Maisonnave, D.S. Azambuja, G.E. Englert, Surf. Coat. Technol. 202 (2008) 5591-6001.

[3] S.S. Pathak, A.S. Khanna, T.J.M. Sinha, Prog. Org. Coat. 60 (2007) 211-218.

[4] V. Palanivel, Y. Huang. W.J.V. Ooij, Prog. Org. Coat. 53 (2005) 153-168.

[5] R.T. Foley, Corros. Sci. 42 (1986) 277-288.

[6] M.W. Kendig, A.J. Davenport, H.S. Issacs, Corros. Sci. 34 (1993) 41-49.

[7] B.R.W. Hinton, D.R. Arnott, N.E. Ryan, Mater. Forum 7 (4) (1984) 211-217.

[8] D. Zhao, J. Sun, L. Zhang, Y.T.J. Li, J. Rare Earths 28 (1) (2010) 371-374.
[9] A. Kumar Mishra, R. Balasubramaniam, Corros. Sci. 49 (3) (2007) 1027-1044. [10] L.E.M. Palomino, P.H. Suegama, I.V. Aoki, Z. Pászti, H.G. de Melo, Electrochim. Acta 52 (27) (2007) 7496-7505.

[11] W. Pinc, P. Yu, M. O’Keefe, W. Fahrenholtz, Surf. Coat. Technol. 203 (23-25) (2009) 3533-3540.

[12] K. Brunelli, Manuele Dabalà, Irene Calliari, Maurizio Magrini, Corros. Sci. 47 (4) (2005) 989-1000.

[13] A. Decroly, J.-P. Petitjean, Surf. Coat. Technol. 194 (2005) 1-9.

[14] G.P. Bierwagen, D.E. Tallman, Prog. Org. Coat. 41 (2001) 201-216.

[15] J.B. Ledeuil, A. Uhart, S. Soule, J. Allouche, J.C. Dupin, H. Martinez, Nanoscale (2014), http://dx.doi.org/10.1039/c4nr03211j.

[16] C.M. Rangel, T.I. Paiva, P.P. da Luz, Surf. Coat. Technol. 202 (2008) 3396-3402

[17] X. Yu, G. Li, J. Alloys Comp. 364 (2004) 193-198.

[18] L.S. Kasten, J.T. Grant, N. Grebasch, N. Voevodin, F.E. Arnold, M.S. Donley, Surf. Coat. Technol. 140 (2001) 11-15.

[19] R.G. Buchheit, S.B. Mamidipally, P. Schmutz, H. Guan, Corrosion 58 (2002) $3-14$.

[20] J.P. Holgado, R. Alvarez, G. Munuera, Appl. Surf. Sci. 161 (2000) 301-315.

[21] A. Pfau, K.D. Schierbaum, Surf. Sci. 321 (1994) 71-80.

[22] M.F. Montemor, A.M. Simoes, M.G.S. Ferreira, M.J. Carmezim, Appl. Surf. Sci. 254 (2008) 1806-1814.

[23] Y.A. Teterin, A.Y. Teterin, A.M. Lebedev, I.O. Utkin,. Electron. Spectrosc. Relat. Phenom. 88-91 (1998) 275-279.

[24] J.Z. Shyu, K. Otto, W.L.H. Watkins, G.W. Graham, J. Catal. 114 (1988) 22

[25] A.E. Hughues, J.D. Gorman, P.J.K. Paterson, Corros. Sci. 38 (1996) 1957-1976.

[26] -K. Bak, L. Hilaire, Appl. Surf. Sci. 70-71 (1993) 191-195.

[27] A. Kotani, T. Jo, J.C. Parlebas, Adv. Phys. 37 (1988) 37-85.

[28] J.Z. Shyu, K. Otto, W.L.H. Watkins, G.W. Graham, Catalysis 114 (1988) 23-33.

[29] P. Campestrini, H. Terryn, A. Hovestab, J.H.W. de Wit, Surf. Coat. Technol. 176 (2004) 365-381.

[30] L.E.M. Palomino, I.V. Aoki, H.G. de Melo, Electrochim. Acta 51 (2006) 5943-5953.

[31] Z. Liu, P.H. Chong, A.N. Butt, P. Skeldon, G.E. Thompson, Appl. Surf. Sci. 247 (1-4) (2005) 294-299.

[32] J.A. DeRose, T. Suter, A. Bałkowiec, J. Michalski, K.J. Kurzydlowski, P. Schmutz, Corros. Sci. 55 (2012) 313-325.

[33] M. Dabala, L. Armaelao, A. Buchberger, I. Calliari, Appl. Surf. Sci. 172 (2001) 312-322.

[34] A.J. Aldykiewiczs, A.J. Davenport, H.S. Isaacs, J. Electrochem. Soc. 143 (1) (1996) 147

[35] S.A. Hayes, Pu Yu, T.J. O’Keefe, M.J. O’Keefe, J.O. Stoffer, J. Electrochem. Soc. 149 (12) (2002) C623-C628 